\title{
High-throughput avian molecular sexing by SYBR green-based real-time PCR combined with melting curve analysis
} Hsueh-Wei Chang*1,2, Chun-An Cheng ${ }^{3}$, De-Leung Gu${ }^{1}$, Chia-Che Chang ${ }^{4}$, San-Hua Su${ }^{1}$, Cheng-Hao Wen ${ }^{1}$, Yii-Cheng $\mathrm{Chou}^{5}$, Ta-Ching Chou ${ }^{6}$, Cheng$\mathrm{Te} \mathrm{Yao}^{7,8}$, Chi-Li Tsai ${ }^{7,9}$ and Chien-Chung Cheng*1

Address: ${ }^{1}$ Faculty of Biomedical Science and Environmental Biology, Kaohsiung Medical University, Kaohsiung, Taiwan, ${ }^{2}$ Graduate Institute of Natural Products, College of Pharmacy, Kaohsiung Medical University, Kaohsiung, Taiwan, ${ }^{3}$ College of Life Science, National Tsing Hua University, HsinChu, Taiwan, ${ }^{4}$ Institute of Biomedical Sciences, National Chung Hsing University, Taichung, Taiwan, 5 Institute of Biotechnology, Chung Hwa College of Medical Technology, Tainan, Taiwan, 'Institute of Ecology and Evolutionary Biology, National Taiwan University, Taipei, Taiwan, ${ }^{7}$ Taiwan Endemic Species Research Institute, Nantou, Taiwan, ${ }^{8}$ Institute of Biodiversity, National Cheng Kung University, Tainan, Taiwan and ${ }^{~}$ Department of Life Sciences, National Chung Hsing University, Taichung, Taiwan

Email: Hsueh-Wei Chang* - changhw@kmu.edu.tw; Chun-An Cheng - yotseal@yahoo.com.tw; De-Leung Gu - ed0958719325@yahoo.com.tw; Chia-Che Chang - chia_che@dragon.nchu.edu.tw; San-Hua Su - trp9999@hotmail.com; Cheng-Hao Wen - joholan2005@gmail.com; YiiCheng Chou - ycls.hiokchi@msa.hinet.net; Ta-Ching Chou - tcchou55@yahoo.com.tw; Cheng-Te Yao - yaoct@tesri.gov.tw; Chi-

Li Tsai - tcl@tesri.gov.tw; Chien-Chung Cheng* - wn7a1001@kmu.edu.tw

* Corresponding authors

Published: 12 February 2008

BMC Biotechnology 2008, 8:12 doi:10.1/86/1472-6750-8-12
Received: 28 September 2007

Accepted: 12 February 2008

This article is available from: http://www.biomedcentral.com/I472-6750/8/12

(C) 2008 Chang et al; licensee BioMed Central Ltd.

This is an Open Access article distributed under the terms of the Creative Commons Attribution License (http://creativecommons.org/licenses/by/2.0), which permits unrestricted use, distribution, and reproduction in any medium, provided the original work is properly cited.

\begin{abstract}
Background: Combination of CHD (chromo-helicase-DNA binding protein)-specific polymerase chain reaction (PCR) with electrophoresis (PCR/electrophoresis) is the most common avian molecular sexing technique but it is lab-intensive and gel-required. Gender determination often fails when the difference in length between the PCR products of CHD-Z and CHD-W genes is too short to be resolved.
\end{abstract}

Results: Here, we are the first to introduce a PCR-melting curve analysis (PCR/MCA) to identify the gender of birds by genomic DNA, which is gel-free, quick, and inexpensive. Spilornis cheela hoya (S. c. hoya) and Pycnonotus sinensis (P. sinensis) were used to illustrate this novel molecular sexing technique. The difference in the length of CHD genes in S. c. hoya and P. sinensis is 13-, and 52-bp, respectively. Using Griffiths' P2/P8 primers, molecular sexing failed both in PCR/electrophoresis of S. c. hoya and in PCR/MCA of S. c. hoya and P. sinensis. In contrast, we redesigned sex-specific primers to yield 185- and II2-bp PCR products for the CHD-Z and CHD-W genes of S. c. hoya, respectively, using PCR/MCA. Using this specific primer set, at least 13 samples of $S$. c. hoya were examined simultaneously and the Tm peaks of CHD-Z and CHD-W PCR products were distinguished.

Conclusion: In this study, we introduced a high-throughput avian molecular sexing technique and successfully applied it to two species. This new method holds a great potential for use in high throughput sexing of other avian species, as well. 


\section{Background}

Real-time PCR (polymerase chain reaction) is a wellestablished method for RNA quantification [1,2] and genomic DNA analysis [3-6]. Several analytical methods have been employed to detect PCR products. The most popular, the TaqMan assay [7], is a hybridization-based method with high specificity, but it is relatively expensive. Another method is based on the double-stranded DNA binding ability $[8,9]$ of fluorescent dye SYBR Green I. The amount of PCR products (amplicons) can be detected in real-time in both methods by measuring fluorescence levels from the cycle threshold $(\mathrm{Ct})$. Both types of analyses are potentially fast and sensitive but the SYBR Green I dye is more cost-effective than the TaqMan probe.

Recently, SYBR green real-time quantitative PCR has been applied to investigate the mRNA expression in birds. For example, the dosage compensation of Z-linked gene expressions was reported $[10,11]$. However, to our knowledge, real-time PCR has not been applied in genomic DNA studies such as the molecular sexing of birds. In general, the molecular sexing of birds depends on the difference in the length of CHD genes when comparing a universal CHD primer pair P2/P8 [12]. Traditionally, a single $C H D-Z$ band is found in males and two bands in females [12] after electrophoresis (female, ZW; male, ZZ) when analyzing $C H D-Z$ and $C H D-W$ genes. Since realtime PCR can monitor the PCR products quantitatively and robustly without the need for gel electrophoresis, the advantages of real-time PCR can be utilized to evaluate avian molecular sexing using the P2/P8 primers. However, SYBR green real-time PCR alone cannot distinguish the individual fluorescence values from different PCR products mixed in the same well. Therefore, this disadvantage of SYBR green real-time PCR alone hinders its utility in molecular sexing using CHD-based primers.

Fortunately, the fluorescence detection problem of SYBR green real-time PCR may be hurdled by subsequent coupling with SYBR green-based melting curve analysis (MCA). MCA was originally used to confirm PCR product identity and to differentiate between specific and non-specific PCR products [13]. Although MCA can be used to differentiate between specific PCR products of $C H D-Z$ and $C H D-W$ genes, genes vary among species and the difference in length of the PCR products of $C H D-Z$ and $C H D$ $W$ in some cases will be too close to allow for precise sexing. For example, the length of $C H D-Z$ and $C H D-W$ products are too close in the case of the Black-faced Spoonbill (Platalea minor) [14], Tawny owl [12] and kiwi ratite (Apteryx spp) [15]. We found similarly close length differences in at least nine species of birds with $C H D-Z$ and $C H D-W$ gene records in Genbank: in the CHD- $Z$ and $C H D-W$ genes (accession nos. = length difference) for Accipiter gentilis AB096144, AB096143 (5-bp), Milvus migrans $\underline{\mathrm{AB} 096142}, \underline{\mathrm{AB} 096141}$ (2-bp), Circaetus gallicus $\underline{\mathrm{AY} 313610}, \underline{\mathrm{AY} 313609}$ (9-bp), Spizaetus nipalensis $\underline{\mathrm{AB} 096150}, \underline{\mathrm{AB} 096149}$ (8-bp), Gyps indicus DQ156155, DQ156156 (6-bp), Gyps bengalensis DQ156153, DQ156154 (5-bp), Accipiter nisus AB096152, AB096151 (4-bp), Circus spilonotus $\underline{\mathrm{AB} 096146}, \underline{\mathrm{AB} 096145}$ (4-bp), and Aquila chrysaetos AB096148, respectively. Therefore, a difference between the bands would be too difficult to resolve using agarose gel electrophoresis. Alternatively, polyacrylamide gels may provide sufficient resolution to discriminate between $C H D-Z$ and $C H D-W$ products for some species $[12,15]$. Yet, it is still time-consuming and it makes high-throughput screening of avian molecular sexing more difficult.

In this study, two different species of birds, Spilornis cheela hoya and Pycnonotus sinensis, were chosen as examples to evaluate the P2/P8 primer and a redesign of the sex-specific primers for CHD-Z and CHD-W genes of S. c. hoya using real-time PCR/MCA. Overall, the aim of this study was to develop a rapid and high-throughput SYBR greenbased real-time PCR assay that would distinguish male and female birds via real-time PCR and unique melting curve profiles.

\section{Methods \\ Sample collection and blood DNA extraction}

A scientific and banding permit number 96YULI032 was issued by the Council of Agriculture of Taiwan pursuant to the Wildlife Conservation Law of Taiwan. Thirteen banded Formosan Crested Serpent Eagles (Spilornis cheela hoya, S. c. hoya), numbered Bd6 and Bds12 24, were collected with official permission from the Kenting National Park (21 $55^{\prime} \mathrm{N}$ and $\left.120^{\circ} 49^{\prime} \mathrm{E}\right)$, Taiwan. Bd6 and Bd 15 of $S$. c. hoya were used for the female positive control of molecular sexing based upon their behavior of playing parts in incubation, brooding and feeding. Two Chinese Bulbuls (Pycnonotus sinensis, P. sinensis) numbered 3424 (female) and 927 (male) were provided by the Taiwan Endemic Species Research Institute. Blood DNA was extracted immediately after sample collection using a Qiagen blood kit and stored at $-20^{\circ} \mathrm{C}$ until needed.

\section{PCR and primary molecular sexing by P2/P8 primers}

The universal P2/P8 primer pair [12] for avian molecular sexing was used for $S$. c. hoya and $P$. sinensis species. The primer sequence information is: forward primer P2 (5'TCTGCATCGCTAAATCCTTT-3') and the reverse primer P8 (5'-CTCCCAAGGATGAGRAAYTG-3'). DNA samples were added to a modified PCR reaction mixture $(10 \mu \mathrm{l})$ containing $1 \times$ PCR buffer, $1.5 \mathrm{mM} \mathrm{MgCl}_{2}, 0.2 \mathrm{mM}$ dNTPs, 0.7U Taq enzyme (Invitrogen corp.), $0.16 \mu \mathrm{M}$ primers mix (1:1), and 10-20 ng DNA. The PCR program was followed: $94^{\circ} \mathrm{C}(4 \mathrm{~min}) ; 5$ cycles of $94^{\circ} \mathrm{C}(30 \mathrm{~s}), 47^{\circ} \mathrm{C}(30$ 
s), $72^{\circ} \mathrm{C}(30 \mathrm{~s}) ; 49$ cycles of $94^{\circ} \mathrm{C}$ for $(30 \mathrm{~s}), 46^{\circ} \mathrm{C}(20 \mathrm{~s})$, $72^{\circ} \mathrm{C}(20 \mathrm{~s})$; and $72^{\circ} \mathrm{C}(5 \mathrm{~min})$.

\section{TA cloning and nucleotide sequence analysis for CHD-Z and CHD-W genes}

For S. c. hoya, P2/P8 PCR products were gel isolated (MiniElute gel extraction kit, QIAGEN), cloned (pGEM -T Easy TA Cloning, Promega) and sequenced. The female and male birds were selected for $C H D-W$ and $C H D-Z$ abundant sources because the CHD- $Z$ and $C H D-W$ PCR products were hard to resolve in regular agarose gel. The sequencing results for the P2/P8 PCR products of S. c. hoya are shown in Fig. 1. For P. sinensis, the CHD-Z and CHD$W$ PCR products were easy to resolve in regular agarose gel without TA cloning technique. The length difference between $C H D-Z$ and $C H D-W$ PCR products using P2/P8 primers is 13- and 52-bp for $S$. c. hoya and P. sinensis, respectively.

\section{Secondary molecular sexing}

An alignment performed with Biology Workbench 3.2 at the San Diego Supercomputer Center (SDSC) [16] is shown in Fig. 1. The primers for $C H D-Z$ - and $C H D-W$-specific PCR of S. c. hoya were redesigned as follows: $C H D-W-$ F: 5-GAGATGGAGTCACTATCAGATCC-3, CHD-W-R: 5GGTTTTCACACATGGCACA-3; CHD-Z-F: 5-CATTAAAGCTGATCTGGAATTTC, CHD-Z-R: 5-TTTTTTCCTTTTCTGAACACATATTT-3. The lengths for PCR products amplified by $C H D-W-\mathrm{F} / C H D-W-\mathrm{R}$ and $C H D-W-$ $\mathrm{F} / C H D-W$-R are 185- and 112-bp, respectively. The same
PCR conditions as described above were used and the PCR program was modified: denaturation for $3 \mathrm{~min}$ at $95^{\circ} \mathrm{C}$ followed by 45 cycles of denaturation at $95^{\circ} \mathrm{C}$ for $30 \mathrm{~s}$; annealing at $58^{\circ} \mathrm{C}$ for $30 \mathrm{~s}$; and extension at $72^{\circ} \mathrm{C}$ for $20 \mathrm{~s}$.

\section{Real-time PCR and melting curve analysis (MCA)}

Real-time PCR was performed using MyiQ (Bio-Rad Laboratories, Hercules, CA). The programs for each PCR reaction, including P2/P8 primers for S. c. hoya and P. sinensis, and CHD-Z- and CHD-W-specific primers for S. c. hoya, are described above. After completion of the PCR reaction, a melting curve was recorded by holding at $95^{\circ} \mathrm{C}$ for $1 \mathrm{~min}$, cooling to $55^{\circ} \mathrm{C} 1 \mathrm{~min}$, and then heating slowly at $0.5^{\circ} \mathrm{C} / \mathrm{s}$ until $95^{\circ} \mathrm{C}$ under maximal ramp rate by default in MyiQ instrument (80 repeats of counts). The melting peaks were plotted by the - $\mathrm{dF} / \mathrm{dT}$ versus $\mathrm{T}$ formula (F is fluorescence; $\mathrm{T}$ is temperature).

\section{Control analysis of amplification product}

To confirm the presence and purity of amplicons, PCR products were resolved on a $4 \%$ agarose gel, stained with ethidium bromide, and photographed.

\section{Results \\ Molecular sexing of S. c. hoya and P. sinensis using P2/P8 primers and its gel electrophoresis}

To test the feasibility of the P2/P8 primers in sexing of $S$. c. hoya and $P$. sinensis, we first performed a regular PCR reaction using this primer pair followed by gel electrophoresis, as shown in Fig. 2. For S. c. hoya, the CHD-W
S. c. hoya-w
CACGTTTTTTTGGTCGTTTTCTTTCCGAGATGGAGTCACTATCAGATCCAGAATATCTTC
CACGTTTTTAGGCCGTTTCTTTCTGAGATGGAGTCACTATCAGATCCA GAGTATCTTC
s. c. hoya-z
TGCTCCTACTGCGTTTCCCTTCACTTCCATTAAAGCT GATCTGGAATTTCAGATTAAGTA
S. c. hoya-w
$\underset{\text { TGCTCCTACTGCGTCTCCCTTCACTTCCATTAAAGCTGATCTGGAATTTCAGAATAGGTA }}{\stackrel{\text { CHD-Z-F }}{\longrightarrow}}$
S. c. hoya-z
S. C. hoya-W
GTTCAAAGCTACGT GACTAAAACATTTTATTAATGTGTTATCTAGCCTGTCAAAAAT GGG
s. c. hoya-z
GTTCAAAGCTATGTGATTAACAACCATAAGTAAAGTTTTACCTAGCCTGTCAAAAATATG CHD-W-R
S. c. hoya-W
S. c. hoya-z
GGAAT GGGGGGGTGTGCCATGTGT GAAAACCACCCAACCCAAAAGTACAAGACAAGACAA TGTTCAGAAAAG------ GAAAAAAAAAACCAACTTAAAAAC-CAAAACCCAACAA

\section{CHD-Z-R}
s. c. hoya-W CAGCAATGAAAAAACAAACAAAA--AACAACAACAAAAAAATCAAAGTTAGTTGGTCAAA
s. c. hoya-z CAACCCCCAACAAAGAAACTAAACCAATAGCAATATAAAAGCACAAGTCA----GTCAAA
s. c. hoya-W ACCCAGAgAtACCTGTTTTGCACAgtTCCTCATCCTTGGGAGA
s. c. hoya-z ACCAAGAGACACCTGTTTTGCACAATTCCTCATCCTTGGGAGA

\section{Figure I}

Alignment of CHD-W and CHD-Z sequences from S. c. hoya. Sequences are derived from the complementary version of their Genbank accession numbers DQ885237 and DQ885238, respectively. 


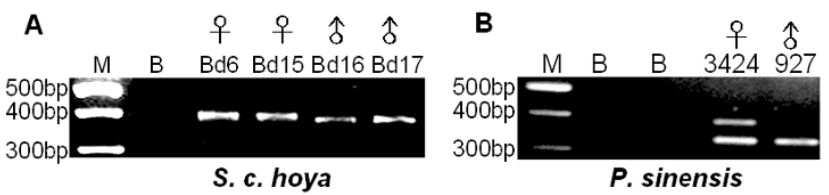

Figure 2

Gel view for PCR product amplified by primer sets P2/P8 in S. c. hoya and P. sinensis. Bds 6, I5, and 3424 are the female positive control. M, I00-bp marker; B-blank.

and $C H D-Z$ gene products were unsolved in 3\% agarose gel (Fig. 2A). After cloning as described in Materials and Methods, the CHD-W and CHD-Z genes of $S$. c. hoya were sequenced and submitted to Genbank with accession nos. DQ885238 and DQ885237, respectively. The difference in length (13-bp) between these CHD-W and $C H D-Z$ genes of $S$. c. hoya was too short to resolve in $4 \%$ agarose gel. In contrast, in the case of $P$. sinensis, two distinct PCR products corresponding to $C H D-Z$ and $C H D-W$ genes were amplified and could be resolved in regular agarose gels (Fig. 2B). These two bands-i.e. $C H D-W$ and $C H D-Z$ gene products-were purified, sequenced and submitted to Genbank with accession nos. EF582413 and EF582412, respectively. There is a 52-bp length difference between the CHD-W and CHD-Z genes of $P$. sinensis. Accordingly, the P2/P8 primer set is informative for molecular sexing of $P$. sinensis but it is not suitable for the sex-specific primers for $S$. c. hoya. In short, the gender identification of $S$. $c$. hoya needs to be improved.

\section{Real-time PCRIMCA of S. c. hoya and P. sinensis using P2I P8 primers}

Real-time PCR analyses for S. c. hoya (Fig. 3A) and P. sinensis (Fig. 3C) demonstrated that the PCR reactions were successful. Reaction products were also confirmed by gel electrophoresis (data not shown). However, SYBR greenfluorescence of PCR products for $C H D-Z$ and $C H D-W$ genes were counted totally rather than individually. Con-

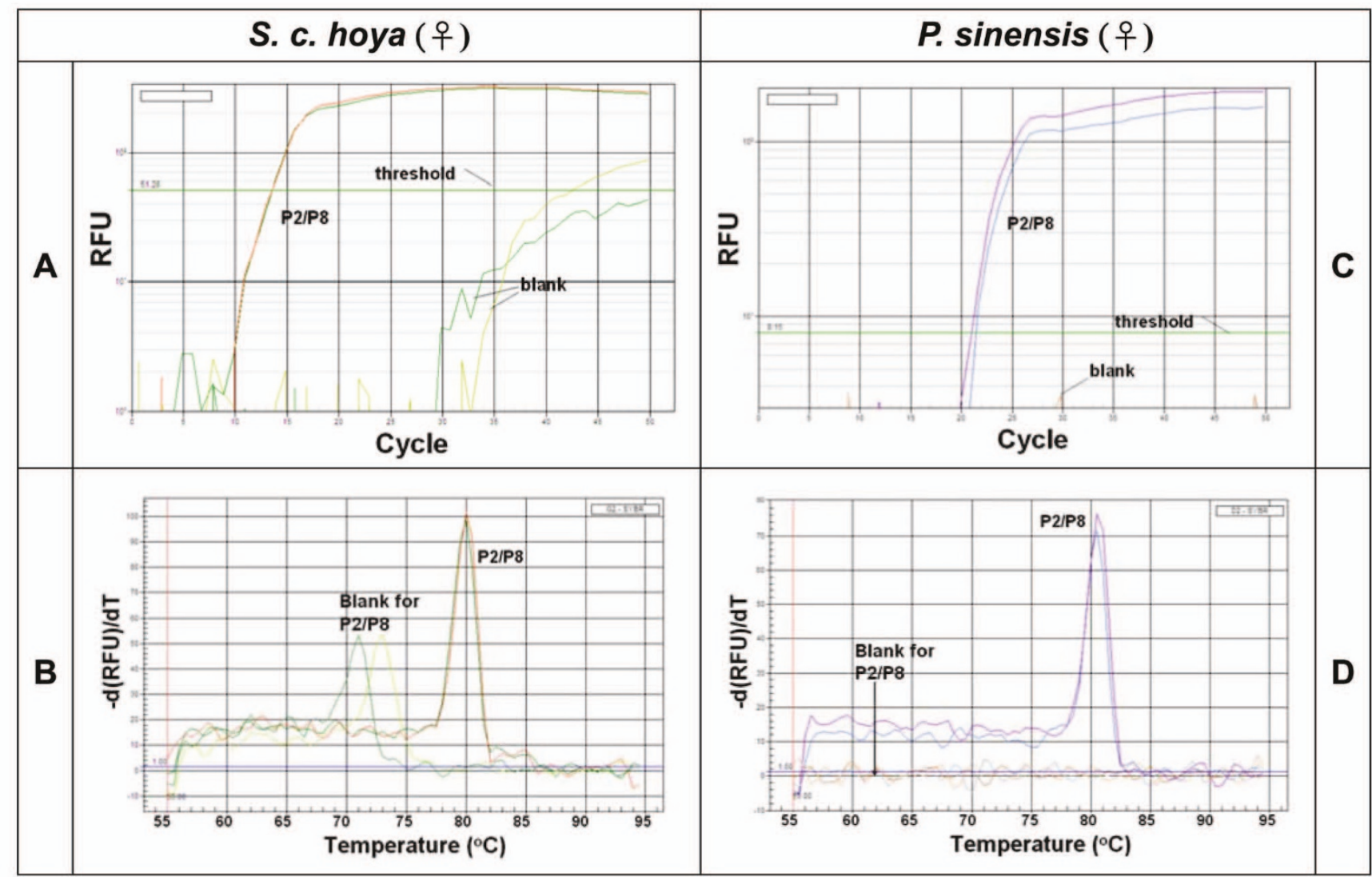

Figure 3

Real-time PCR/MCA using primer sets P2/P8. DNAs were chosen from S. c. hoya sample Bd6 (A, B) and P. sinensis sample 3424 (C, D), which are the ecology female control. $(A, C)$ Real-time PCR data. (B, D) Data of MCA. The Tm of P2/P8 PCR products of $S$. C. hoya and $P$. sinensis is about 80.0 and $80.5^{\circ} \mathrm{C}$, respectively. These data are collected from duplicated experiments. RFU, Relative fluorescence unit. 
sequently, the real-time PCR results cannot clearly provide evidence that $C H D-Z$ or/and $C H D-W$ genes are present individually or are present in both of them.

After performing MCA on the PCR products of $C H D-Z$ and CHD-W genes of $S$. $c$. hoya amplified by P2/P8 primers in the same well, we found that there was a single peak (Tm) at $80^{\circ} \mathrm{C}$ for the P2/P8 PCR products in S. c. hoya, which could be distinguished from a nonspecific amplification with $\mathrm{Tm}$ at $72-74^{\circ} \mathrm{C}$ (Fig. 3B). The nonspecific PCR products were the primer-dimers confirmed by gel electrophoresis (data not shown). To our surprise, only a single peak at $80.5^{\circ} \mathrm{C}$ was found in $P$. sinensis for $P 2 / P 8$ amplification (Fig. 3D) although the length difference of $C H D-Z$ and $C H D-W$ was 52-bp and two distinct bands were visualized (as shown in Fig. 2B). Therefore, it is unsuitable to perform SYBR green-based real-time PCR with MCA by P2/P8 primers in the example of S. c. hoya and P. sinensis.

\section{Redesign of sex-specific primers in S. c. hoya}

In order to improve molecular sexing using real-time PCR and melting curve assay, we redesigned the sex-specific primers. In the example of S. c. hoya, we aligned $C H D-Z$ and $C H D-W$ gene sequences from Genbank accession nos. DQ885238 and DQ885237 and designed sex-specific primers for both of them (Fig. 1). The PCR products of $C H D-Z$ and $C H D-W$ genes are 185-bp and 112-bp, respectively. This elongated length difference between each of them was designed to make it more suitable for melting curve assay. Since the primer sets for $C H D-Z$ and $C H D-W$ genes overlapped, it was not suitable to perform PCR reactions in the same PCR-well (data not shown).

\section{Validation of sex-specific primers in S. c. hoya}

To examine the effect of sex-specific primers on the molecular sexing by our protocol, we performed PCR reactions using $C H D-Z$ and $C H D-W$ primers in different PCR-wells. With our protocol, the female bird (ZW genotype) is positive for both PCR reactions using $C H D-Z-F / R$ and $C H D-$ $W$-F/R primers. However, the male bird ( $Z Z$ genotype) is positive only for PCR reactions using $C H D-Z-F / R$ primers and not for PCR reactions using $C H D-W-F / R$ primers. For instance, the predicted female birds named $\mathrm{Bd} 15$ and Bd17 showed a single band for both CHD-W (Fig. 4A) and CHD-Z (Fig. 4B) PCR products with correct size 185bp and 112-bp, respectively. For predicted male birds, the $\mathrm{Bd} 16, \mathrm{Bd} 21$ and $\mathrm{Bd} 22$ showed a single band of $C H D-Z$ PCR products with the correct size of 112-bp (Fig. 4B). In this case, the male birds showed some weak bands for non-specific PCR products and primer-dimers using CHD-W-F/R primers (Fig. 4A). The size of these non-specific PCR products was not unlike that of $C H D-W-\mathrm{F} / \mathrm{R}$ primers. Some of these bands (marked with a star symbol) were sequenced and found to be unrelated to CHD genes by BLAST analysis (data not shown).

\section{High-throughput molecular sexing of S. c. hoya- Real-time PCRIMCA}

As real-time PCR is inherent with the high-throughput feature, we further evaluated the potential of our protocol for high-throughput avian molecular sexing by performing real-time PCR reactions on 13 different samples simultaneously. As shown in Fig. 4C, seven different individuals of $S$. $c$. hoya were identified to be females, as they exhibited both $C H D-Z$ - and $C H D-W$-specific peaks at $75^{\circ} \mathrm{C}(\mathrm{Z}-112)$ and $79^{\circ} \mathrm{C}(\mathrm{W}-185)$, respectively. On the other hand, six different individuals of $S$. $c$. hoya were identified as males, as only the $C H D$-Z-specific peak at $75^{\circ} \mathrm{C}$ was shown in Fig. 4D. Furthermore, it was noted that the non-specific products $(\mathrm{W}-185)$ amplified by $C H D-W$-specific primers were discriminate to the $C H D-Z$ and $C H D-W$-specific products because of the wrong Tm value (Fig. 4D). Taken together, although only thirteen samples of $S$. c. hoya were tested in this study, our results clearly demonstrate the feasibility of our protocol for high-throughput molecular sexing of birds. 4). Further details on all the tested samples shown in Fig. 4 are shown individually in the supplementary information (see additional file 1).

\section{Discussion \\ Application of real-time PCRIMCA for traditional PCR- electrophoresis methods using CHD gene-related primers} P2/P8 [12], 1237L/1272H [17] and 2550F/2718R [18] primer sets have been reported in the molecular sexing of birds. However, they no study has used melting curve asssay for high-throughput molecular sexing. Theoretically, MCA is able to provide the Tm value for each PCR product even if different PCR products are mixed in the same well. The use of MCA eliminates the necessity for agarose gel electrophoresis because the melting temperature (Tm) of the specific amplicon is analogous to the detection of an electrophoretic band. In this study, we focused on the issue in the case of $\mathrm{P} 2 / \mathrm{P} 8$ primers. The fact that MCA cannot detect the individual PCR products of $C H D-Z$ and $C H D-W$ genes by $\mathrm{P} 2 / \mathrm{P} 8$ primers could be due to the short length difference (13-bp for $S$. c. hoya) between these two DNA fragments (Fig. 3B).

Recently, the lengths of $C H D-W$ and $C H D-Z$ genes of forty-four avian species have been reported [19]. After calculation, we found that the average length difference of $C H D-W$ and CHD-Z genes using P2/P8 primers among these species is about $40-\mathrm{bp}(\mathrm{n}=44$, ranging from 10 - to 80-bp). Here, we chose $P$. sinensis as an example to mimic the most common PCR length difference of $C H D-Z$ and $C H D-W$ genes using P2/P8 primers. Its PCR length difference is 52-bp but two peaks with different Tm values were still not shown by MCA (Fig. 3D). Perhaps 52-bp is still too short for resolution in melting curve assays for $C H D$ $W$ and CHD-Z genes of $P$. sinensis. In addition, the base 

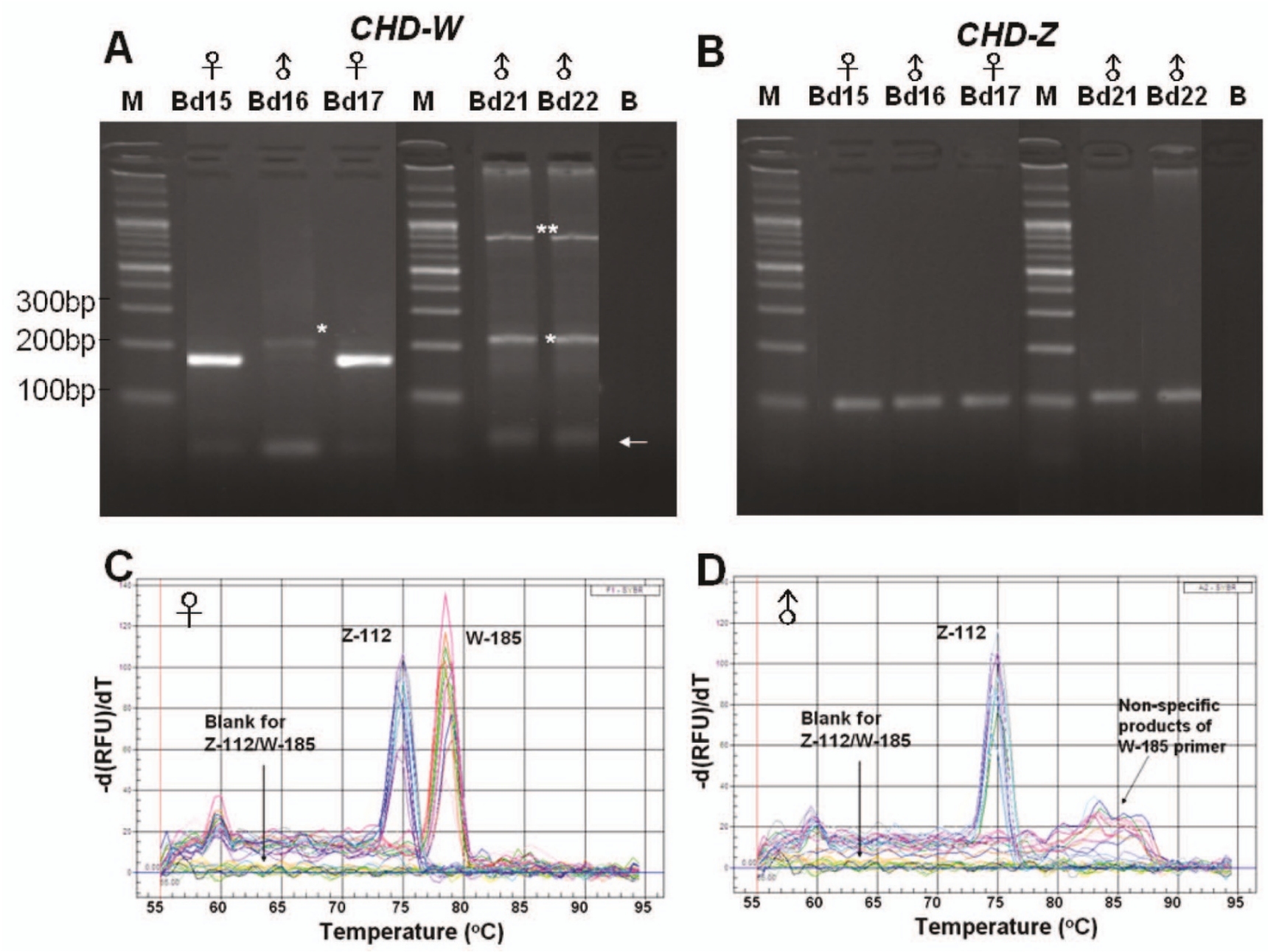

\section{Figure 4}

Representative gel view and MCA using sex-specific primers of S. c. hoya. PCR products with I85- and II2-bp amplified by (A) CHD-W-F/R and (B) CHD-Z-F/R primers in different PCR-wells were run in 4\% agarose gel, respectively. The arrow of Fig. 4A indicates the remaining primers or primer-dimers of PCR. Non-specific products of W-I85 indicated with star symbols were only occurred in male samples. (C, D) demonstration for high-throughput molecular sexing of multiple $S$. c. hoya samples using MCA. All data are performed in duplicate. (C) 7 females (Bds 12, 14, I5, 17, 19, 20, and 23) and (D) 6 males (Bds I3, I6, I8, 21 , 22, and 24) were included. Z-III 2 and W-I85 represent the primer mixtures for CHD-Z-F/CHD-Z-R (II I-bp) and CHD-W-F/ CHD-W-R (I85-bp). The Tm value for Z-II 2 and $W-185$ is $75.0^{\circ} \mathrm{C}$ and $79^{\circ} \mathrm{C}$, respectively. The Tm of non-specific products of $\mathrm{W}-\mathrm{I} 85$ is greatly larger than $79^{\circ} \mathrm{C}$.

composition and the concentration of SYBR green may play a role in Tm value and the resolution of MCA [8]. More importantly, MCA is also dependant on base pair positioning and juxtapositioning. It is possible that MCA using P2/P8 primers cannot be applied to the sexing of most bird species. In fact, our data indicated the limitations of $\mathrm{P} 2 / \mathrm{P} 8$ primers, underlying the necessity of sexspecific primers for avian molecular sexing. Accordingly, we chose $S$. $c$. hoya as the example to evaluate the effect of sex-specific primers (Fig. 1) in avian molecular sexing by SYBR green-based real-time PCR followed by MCA. However, these melting curve assays were performed by a
MyiQ real-time PCR machine (Bio-rad). We cannot exclude the possibility that some brands of real-time PCR machines may have different resolution. Also, high resolution melting (HRM) analysis [20,21] may resolve subtle differences even with short length differences.

\section{Improvement for real-time PCR combined with MCA}

Using our redesigned sex-specific primers $C H D-Z-F / C H D-$ $Z$-R and $C H D-W$-F/CHD-W-R of S. c. hoya, we calculated a 73-bp length difference between two PCR products (Fig. 1 ). This length difference proved to be long enough for resolution by MCA as shown in the results of Fig. 4. Fur- 
thermore, this gender identification method had validated by anatomical inspection (see additional file 2). However, it is possible that cross-interference of four primers mixed together in the same well hampered optimal PCR reaction (data not shown). Therefore, PCR reaction amplified by CHD-Z-F/CHD-Z-R and CHD-W-F/ $C H D-W$ - R was analyzed in different PCR-wells. This strategy proved to be successful (Figs. 4A and $4 \mathrm{~B}$ ) to determine the gender of $S$. c. hoya in a high-throughput manner (Figs. 4C and 4D).

\section{Nonspecific peaks in MCA}

Nonspecific amplification is mainly caused by nonspecific primers but sometimes may also be due to a low annealing temperature and high concentrations of template DNA, $\mathrm{Mg}^{2+}$, polymerase, or dNTPs [22]. Fortunately, in our study the Tm shift derived from the PCR product polymerization can be distinguished from nonspecific amplification. Accordingly, the nonspecific amplifications have some distinct peaks in the melting curves and show some bands with different MWs from PCR products of $C H D-Z$ and $C H D-W$ genes (Figs. $4 \mathrm{~B}$ and $4 \mathrm{D}$ ).

\section{Other methods for molecular avian sexing}

Increasing evidence $[15,18,23-25]$ shows that the gender of some avian species cannot be identified by the P2/P8 PCR-based protocol [12] due to the limited difference in the length of intron for $C H D-Z$ and $C H D-W$. This limitation has been overcome by some methods such as redesigned PCR primers [18] and our proposed approach, as well as PCR-RFLP [23,25], RAPD [26] and AFLP [27] fingerprintings. Some of these methods may also have the potential for high-throughput application of avian molecular sexing, but their gel electrophoresis step has to be improved. In contrast, our proposed PCR/MCA method is gel-free and only an extra SYBR green I is required compared to a regular PCR cocktail.

\section{Conclusion}

Real-time PCR using SYBR green fluorescence followed by melting temperature determination is a simple and effective way to identify the gender of birds. The essential condition for this powerful molecular sexing method is the presence of $C H D-Z$ and $C H D-W$ sequences allowing the design of sex-specific primers. This work serves as a novel model for the development and use of a one-step, SYBR green-based real-time PCR and melting curve procedure for the rapid and specific detection and verification of the gender of birds using sex-specific or P2/P8 primer sets. Due to its real-time nature, 96- or 384-well plates are available for the real-time PCR machine to perform molecular sexing of birds in a high-throughput manner.

\section{Abbreviations}

NCBI - National Center for Biotechnology Information; BLAST - Basic Local Alignment Search Tool; MCA - melting curve assay; CHD - chromo-helicase-DNA binding protein

\section{Authors' contributions}

$\mathrm{H}-\mathrm{WC}$ and $\mathrm{C}-\mathrm{C}$ Cheng designed the experiment and wrote the manuscript. C-AC and D-LG worked on melting curve assays. C-C Chang improved the real-time PCR performance. S-HS, C-HW, Y-CC worked on DNA extraction and bioinformatics. T-CC, C-TY and, C-LT provided the samples and ecological information. All authors had read and approved the final manuscript.

\section{Additional material}

\section{Additional file 1 \\ Individual profile of melting curve analyses in Fig. 4. All the tested sam- ples shown in Fig. 4 are shown individually in two grouped graphs. Click here for file \\ [http://www.biomedcentral.com/content/supplementary/1472- 6750-8-12-S1.pdf] \\ Additional file 2 \\ Validation the results of our proposed PCR/MCA method by anatomical inspection. The anatomical structure and molecular gender identification of female samples of S. c. hoya were presented. \\ Click here for file \\ [http://www.biomedcentral.com/content/supplementary/1472- 6750-8-12-S2.pdf]}

\section{Acknowledgements}

This work was supported in part by the National Science Council of Taiwan under grants NSC96-2622-B-037-003-CC3 and NSC95-2622-B-037-002CC3 to H-W Chang, and by funds from Kaohsiung Medical University for student training in summer 2007. The authors are also grateful for the help received from representatives at Kenting National Park, Taiwan and the support of real-time PCR machine from Prof. Steven Shoei-Lung Li. We are grateful for the help of Miss Samantha Benton and Mr. Joel Stocker in the preparation of this manuscript.

\section{References}

I. Buckhaults P, Zhang Z, Chen YC, Wang TL, St Croix B, Saha S, Bardelli A, Morin PJ, Polyak K, Hruban RH, Velculescu VE, Shih IM: Identifying tumor origin using a gene expression-based classification map. Cancer research 2003, 63(I4):4|44-4|49.

2. Salani R, Beuberger I, Kurman RJ, Bristow R, Chang HW, Wang TL, Shih IM: Expression of extracellular matrix proteins in ovarian serous tumors. International Journal of Gynecological Pathology 2007, 26(2): $|4|-\mid 46$

3. Randegger CC, Hachler H: Real-time PCR and melting curve analysis for reliable and rapid detection of SHV extendedspectrum beta-lactamases. Antimicrobial agents and chemotherapy 200I, 45(6): $1730-1736$.

4. Wang BG, Huang HY, Chen YC, Bristow RE, Kassauei K, Cheng CC, Roden R, Sokoll LJ, Chan DW, Shih IM: Increased plasma DNA integrity in cancer patients. Cancer research 2003, 63(14):3966-3968. 
5. Ponchel F, Toomes C, Bransfield K, Leong FT, Douglas SH, Field SL, Bell SM, Combaret V, Puisieux A, Mighell AJ, Robinson PA, Inglehearn CF, Isaacs JD, Markham AF: Real-time PCR based on SYBRGreen I fluorescence: an alternative to the TaqMan assay for a relative quantification of gene rearrangements, gene amplifications and micro gene deletions. BMC biotechnology 2003, 3:18.

6. Skow A, Mangold KA, Tajuddin M, Huntington A, Fritz B, Thomson RB Jr., Kaul KL: Species-level identification of staphylococcal isolates by real-time PCR and melt curve analysis. Journal of clinical microbiology 2005, 43(6):2876-2880.

7. Holland PM, Abramson RD, Watson R, Gelfand DH: Detection of specific polymerase chain reaction product by utilizing the 5'----3' exonuclease activity of Thermus aquaticus DNA polymerase. Proc Natl Acad Sci U S A 199I, 88(16):7276-7280.

8. Giglio S, Monis PT, Saint CP: Demonstration of preferential binding of SYBR Green I to specific DNA fragments in realtime multiplex PCR. Nucleic Acids Res 2003, 3 I(22):el 36.

9. Ririe KM, Rasmussen RP, Wittwer CT: Product differentiation by analysis of DNA melting curves during the polymerase chain reaction. Analytical biochemistry 1997, 245(2): 154- 160.

10. McQueen HA, McBride D, Miele G, Bird AP, Clinton M: Dosage compensation in birds. Curr Biol 200 I, I I (4):253-257.

II. Kuroiwa A, Yokomine T, Sasaki H, Tsudzuki M, Tanaka K, Namikawa $\mathrm{T}$, Matsuda $\mathrm{Y}$ : Biallelic expression of Z-linked genes in male chickens. Cytogenet Genome Res 2002, 99( I-4):3 10-3|4.

12. Griffiths R, Double MC, Orr K, Dawson RJ: A DNA test to sex most birds. Mol Ecol I998, 7(8): 107|-1075.

13. Lyon $\mathrm{E}:$ Mutation detection using fluorescent hybridization probes and melting curve analysis. Expert review of molecular diagnostics 200I, I(I):92-10I.

14. Cheng YH, Kuo TF, Lee DN, Weng CF: Sex Identification of the Black-faced Spoonbill (Platalea minor). Zoological Studies 2006, 45(I): 104-II3.

15. Huynen L, Miles J, Lambert D: Unusual electrophoretic mobility of a DNA fragment of the universal 'non-ratite' sexing marker CHD allows sexing of New Zealand's endangered kiwi ratite Apteryx spp. IBIS 2006, I48(I): 167-I68.

16. Biology Workbench 3.2 at the San Diego Supercomputer Center (SDSC) [http://workbench.sdsc.edu/]

17. Kahn NW, John JST, Quinn TW: Chromosome-specific intron size differences in the avian CHD gene provide an efficient method for sex identification in birds. The Auk 1998, II 5(4): 1074-1078.

18. Fridolfsson $A$, Ellegren $\mathrm{H}$ : A simple and universal method for molecular sexing of non-ratite birds. Journal of Avian Biology 1999, 30(1):|16-|2|.

19. Jensen T, Pernasetti FM, Durrant B: Conditions for rapid sex determination in 47 avian species by PCR of genomic DNA from blood, shell-membrane blood vessels, and feathers. Zoo Biology 2003, 22:56I-57I.

20. Wittwer CT, Reed GH, Gundry CN, Vandersteen JG, Pryor RJ: High-resolution genotyping by amplicon melting analysis using LCGreen. Clinical chemistry 2003, 49(6 Pt I):853-860.

21. Montgomery J, Wittwer CT, Palais R, Zhou L: Simultaneous mutation scanning and genotyping by high-resolution DNA melting analysis. Nature protocols 2007, 2(I):59-66.

22. Carbonari M, Sbarigia D, Cibati M, Fiorilli M: Optimization of PCR performance. Trends Genet 1993, 9(2):42-43.

23. Sacchi P, Soglia D, Maione S, Meneguz G, Campora M, Rasero R: A non-invasive test for sex identification in short-toed Eagle (Circaetus gallicus). Molecular and cellular probes 2004, 18(3): 193-196.

24. De volo SB, Reynolds RT, Topinka JR, May B, Antolin MF: Population genetics and genotyping for mark-recapture studies of Northern Goshawks (Accipiter gentilis) on the Kaibab plateau, Arizona. J Raptor Res 2005, 39(3):286-295.

25. Reddy A, Prakash V, Shivaji S: A rapid, non-invasive, PCR-based method for identification of sex of the endangered Old World vultures (white-backed and long-billed vultures) Implications for captive breeding programmes. Current Science 2007, 92(5):659-662.

26. Wu CP, Horng YM, Wang RT, Yang KT, Huang MC: A novel sexspecific DNA marker in Columbidae birds. Theriogenology 2007, 67(2):328-333.
27. Huang CW, Cheng YS, Rouvier R, Yang KT, Wu CP, Huang MC: AFLP fingerprinting for paternity testing in ducks. $\mathrm{Br}$ Poult Sci 2007, 48(3):323-330.
Publish with Bio Med Central and every scientist can read your work free of charge

"BioMed Central will be the most significant development for disseminating the results of biomedical research in our lifetime. "

Sir Paul Nurse, Cancer Research UK

Your research papers will be:

- available free of charge to the entire biomedical community

- peer reviewed and published immediately upon acceptance

- cited in PubMed and archived on PubMed Central

- yours - you keep the copyright
BioMedcentral 